\title{
Motivação no Setor Público: Um Estudo com Servidores do Município de Ponto Novo - BA
}

\author{
Antenor Pedro Domingos Júnior ${ }^{1}$; Milka Alves Correia Barbosa ${ }^{2}$
}

\begin{abstract}
Resumo: O presente trabalho teve como objetivo analisar o nível de motivação dos servidores públicos municipais da cidade de Ponto Novo-Ba, à luz da teoria dos dois fatores de Herzberg. Trata-se de uma pesquisa qualitativa e descritiva, cuja coleta de dados ocorreu por meio de questionários. No que se refere aos fatores que causam a satisfação dos funcionários no ambiente de trabalho, com a análise das respostas, constatou que, os fatores motivacionais tais como reconhecimento, realização, progresso profissional, responsabilidade e trabalho em si, estão de acordo com as expectativas dos servidores, sendo os que mais contribuem para satisfação e motivação no trabalho. A análise dos dados permitiu concluir que os principais fatores (motivacionais e higiênicos) que estimulam a motivação precisam ser vistos com olhares diferentes, ficando incumbida a administração de implantar, complementar e desenvolver programas e políticas de valorização destes servidores.
\end{abstract}

Palavras-Chave: Serviço Público, Motivação, Satisfação.

\section{Motivation in the Public Sector: A Study with Ponto Novo City Servers - BA}

\begin{abstract}
This study aimed to analyze the level of motivation of municipal civil servants of the city of Ponto Novo, in the light of the two-factor theory from Herzberg. It is a qualitative and descriptive study, whose data were collected through questionnaires. With regard to the factors that cause employee satisfaction in the workplace, with the analysis of the responses, it found that the motivational factors such as recognition, achievement, professional advancement, responsibility and work itself, are in line with expectations servers, and those who contribute most to satisfaction and motivation at work. Data analysis concluded that the main factors (motivational and hygienic) that stimulate motivation need to be seen with different looks, being responsible administration to deploy, and develop complementary programs and policies promoting these servers.
\end{abstract}

Keywords: Public Service, Motivation, Satisfaction.

\section{Introdução}

A motivação é um dos temas mais pesquisados na atualidade no campo do comportamento organizacional. Nas organizações, a motivação vem sendo associada ao melhor desempenho dos funcionários e consequentemente, aumento da sua produtividade. Nesse sentido, motivação também pode ser associada à valorização da força de trabalho

Para autores como Bergamini (1997), motivação é uma força que impulsiona o indivíduo na direção de alguma coisa, é um motivo para a ação.Complementando, Chiavenato (2004) afirma que "motivo é tudo aquilo que impulsiona a pessoa a agir de determinada forma ou, pelo menos, que dá origem a uma propensão a um comportamento específico”. Já Rufino (2007, p.8) chama atenção que “os motivos são às vezes, definidos como necessidades, desejos ou impulsos no interior do indivíduo”.

\footnotetext{
${ }^{1}$ Graduado em Administração, Especialista em Gestão de Pessoas. Pós-Graduando em Gestão Pública pela Universidade Federal do Vale do São Francisco-UNIVASF - E-mail: pierrijunior@hotmail.com;

${ }^{2}$ Doutora e Mestre em Administração pela PROPAD/Universidade Federal de Pernambuco - UFPE, Professora adjunta da Universidade Federal de Alagoas, Campus de Arapiraca. Curso de Administração. E-mail: milka.barbosa@univasf.edu.br.
} 
Id on Line Revista Multidisciplinar e de Psicologia

Id on Line Revista Multidisciplinar e de Psicologia

Nessa perspectiva, várias teorias ajudam os gestores, os pesquisadores e as pessoas a compreenderem quais são os fatores que motivam o comportamento das pessoas dentro do seu ambiente de trabalho, destaque-se: a Teoria da Hierarquia das Necessidades (Maslow), a Teoria dos dois Fatores(Herzberg), as Teorias X e Y (McGregor) e a Teoria da Expectativa (Victor Vroom). Em comum, essas abordagens consideram a motivação como algo intrínseco; uma força interna que impulsiona as pessoas a agirem no sentido de buscar algo.Reforçando essa interpretação, Rufino (2007, p.20) afirma que "motivação é um fator interno, que dá início, dirige e integra o comportamento da pessoa".

Dentre as teorias que abordam a motivação, este trabalho terá como referencial a teoria dos dois fatores de Frederick Herzberg, que aborda a relação de motivação e satisfação das pessoas.

Apesar da importância da motivação, sabe-se que em alguns tipos de organização, em especial nos órgãos da administração pública brasileira, essa ainda é uma questão que merece ser melhor abordada. Nos últimos anos, o setor público diante das suas principais funções - fiscalizadora, reguladora, provedora de bens e serviços, redistributiva e estabilizadora, vem buscando desenvolver mecanismos com o objetivo de melhorar a qualidade dos seus serviços prestados, orientando assim, as ações para resolução de problemas ligados a motivação dos servidores ou empregados públicos (BERGUE, 2012).

Para tanto, observa-se o esforço institucional em criar mecanismos eficazes para atender efetivamente aos anseios dos funcionários públicos por meio de programas voltados para a qualificação e melhoria das condições de trabalho, objetivando elevar a motivação desses servidores

Especificamente no âmbito da gestão pública municipal algumas peculiaridades como o grande número de servidores em seus diferentes cargos; as funções e tarefas desempenhadas por eles; a complexidade estrutural da organização que engloba secretarias, departamentos e autarquias dentre outros, confere a motivação certo grau de complexidade.

Considerando esse contexto, o presente trabalho teve como objetivo investigar: quais fatores influenciam o nível de motivação dos funcionários públicos municipais da secretaria de educação de Ponto Novo-BA?

O presente trabalho está organizado em seções, além dessa introdução. Na segunda seção, discute-se teoricamente sobre teorias sobre motivação e motivação no serviço público. Em seguida, descrevem-se os aspectos metodológicos da presente investigação; na seqüência discute-se os dados coletados. Finalmente, algumas reflexões à guisa de considerações finais são apresentadas. 
Id on Line Revista Multidisciplinar e de Psicoloqia

Id on Line Revista Multidisciplinar e de Psicologia

\section{Teorias sobre Motivação}

Chiavenato (2010, p. 191) afirma que "cada um de nós temos motivos para cada ação que praticamos, e o indivíduo trabalha com objetivos que visam atender suas necessidades", as quais são abordadas por teorias de autores como Maslow, Herzberg, McGregor, McClelland e Vroom, que buscaram compreender qual o verdadeiro significado das principais forças que levam à motivação dos indivíduos.

Tais teorias envolvem aspectos biológicos, emocionais e cognitivos da motivação humana e servem de base de estudos para grandes organizações em todo o mundo.O quadro 01 apresenta um resumo dessas abordagens, com respectivos autores e principais conceitos.

Quadro 01:Principais Autores e Teorias de Estudo da Motivação Humana

\begin{tabular}{|c|c|c|}
\hline TEORIA & PRINCIPAIS AUTORES & CONCEITOS \\
\hline $\begin{array}{l}\text { Hierarquia das } \\
\text { Necessidades }\end{array}$ & Abraham H. Maslow & $\begin{array}{l}\text { As necessidades humanas são dispostas como } \\
\text { numa pirâmide, na qual as mais baixas formam } \\
\text { sua base, enquanto no topo situam-se as mais } \\
\text { sofisticadas e estimulantes. } \\
\text { As cinco necessidades básicas são; } \\
\text { necessidades fisiológicas (alimentação, sono, } \\
\text { repouso, abrigo e sexo). } \\
\text { Necessidades de segurança, que é a } \\
\text { manutenção da vida: o ser humano busca } \\
\text { proteger-se de qualquer perigo real ou } \\
\text { imaginário (proteção, tranqüilidade, } \\
\text { estabilidade) } \\
\text { As Necessidades Sociaisestão relacionadas } \\
\text { com a vida do homem na sociedade (amor, } \\
\text { aceitação pelo grupo e interação). } \\
\text { A Auto-Estima diz respeito à necessidade de o } \\
\text { homem estimar a si próprio, são aquelas } \\
\text { relacionadas com o reconhecimento, ao status e } \\
\text { poder. } \\
\text { Depois que as demais necessidades começam a } \\
\text { ser adequadamente satisfeitas, surge, então, as } \\
\text { necessidades de auto-realização, que se } \\
\text { encontram no topo da hierarquia. A auto- } \\
\text { realização é a necessidade de realizar o } \\
\text { máximo de potencial individual }\end{array}$ \\
\hline Teoria X e Y & Douglas McGregor & $\begin{array}{l}\text { Correlação dos conceitos básicos sobre } \\
\text { motivação e proposição de duas visões distintas } \\
\text { do ser humano e suas relações no trabalho; são } \\
\text { duas possibilidades totalmente distintas e } \\
\text { mostram duas formas de gerenciar a } \\
\text { produtividade do indivíduo dentro da } \\
\text { organização. } \\
\text { Na teoria X os colaboradores têm resistências a } \\
\text { responsabilidades e tarefas, o que torna o } \\
\text { trabalho desagradável. Já na teoria Y os } \\
\text { colaboradores são competentes, responsáveis e } \\
\text { criativos e o trabalho é tão natural quando o } \\
\text { lazer. }\end{array}$ \\
\hline
\end{tabular}


Id on Line Revista Multidisciplinar e de Psicologia

Id on Line Revista Multidisciplinar e de Psicologia

\begin{tabular}{|c|c|l|}
\hline $\begin{array}{c}\text { Teoria da Expectativa ou } \\
\text { Instrumentalidade }\end{array}$ & Victor Vroom & $\begin{array}{l}\text { A motivação é resultado de três fatores que } \\
\text { estão nos objetivos particulares de cada } \\
\text { indivíduo. }\end{array}$ \\
& & $\begin{array}{l}\text { Os três fatores são:força do desejo de alcançar } \\
\text { objetivos individuais, relação percebida entre } \\
\text { produtividade e alcance de objetivos } \\
\text { individuais e por último a capacidade percebida } \\
\text { de influenciar seu próprio nível de } \\
\text { produtividade. }\end{array}$ \\
& & $\begin{array}{l}\text { Para Vroom a motivação de produzir é função } \\
\text { das relações entre expectativas e recompensas. }\end{array}$ \\
\hline Teoria da Realização ou & David McClelland & $\begin{array}{l}\text { Há três necessidades que motivam o } \\
\text { comportamento do homem, observadas através } \\
\text { das Necessidades }\end{array}$ \\
Adquiridas & & $\begin{array}{l}\text { do resultado de um teste de nome TPT - Teste } \\
\text { da Percepção Temática: necessidade de } \\
\text { realização; necessidade de associação; } \\
\text { necessidade de poder. }\end{array}$ \\
\hline
\end{tabular}

Fonte: Chiavenato (2004); Rodrigues; Rufino (2007); Vergara (2005).

Como se observa vários pesquisadores se dedicaram aos estudos da motivação apresentando ao longo de vários anos de estudos como resultado, diversas correntes de pensamentos e muitas discussões sobre motivação (RUFINO, 2007), como se ilustrou no quadro 01. Dentre elas, no presente trabalho, optou-se pela abordagem dos dois fatores de Herzberg como principal aporte teórico.

\section{A Teoria dos Dois Fatores de Herzberg}

A teoria dos dois fatores também chamada de teoria da higiene-motivação foi criada na década de 60 por Frederick Herzberg.Na abordagem de Herzberg, há uma diferença entre satisfação e motivação no trabalho. Conforme Rufino(2007, p. 37),

[...]os fatores que levam à satisfação no trabalho são denominados higiênicos. Estes fatores estão relacionados com as condições em que o trabalho é realizado. Os fatores motivacionais são aqueles que estão diretamente relacionados com a tarefa ou o trabalho, influenciam diretamente a produtividade dos membros da organização.

Para Herzberg, a motivação e a satisfação dependem de dois fatores essenciais Os fatores denominados de "higiene" acham-se ligados ao ambiente periférico ou extrínseco ao indivíduo. Existem também fatores que dizem respeito à busca de um máximo de satisfação motivacional. Estes últimos estão ligados ao próprio indivíduo e ao tipo de trabalho que ele desenvolve, configurando-se caracteristicamente como os verdadeiros fatores responsáveis pela motivação intrínseca - são chamados de fatores motivacionais (BERGAMINI, 1997; CHIAVENATO, 2004). 
Os fatores higiênicos ou extrínsecos como também são chamados não levam ao aumento da satisfação do indivíduo no trabalho, mas a sua ausência pode torna o indivíduo insatisfeito. Já os fatores motivacionais de acordo Chiavenato (2004, p. 69),

Refere-se ao conteúdo do cargo, às tarefas e aos deveres relacionados com o cargo em si. Produzem efeito duradouro de satisfação e de aumento de produtividade em níveis de excelência, isto é, acima dos níveis normais. O termo motivação envolve sentimentos de realização, crescimento e de reconhecimento profissional manifestados por meio do exercício das tarefas e atividades que oferecem desafio e significado para o trabalho.

Assim, os fatores motivacionais ou intrínsecos quando são ótimos aumentam a satisfação nas pessoas, porém na falta ou quando são precários provocam uma ausência de satisfação na pessoa. $\mathrm{O}$ quadro 02 apresenta de forma resumida as principais idéias da abordagem de Herzberg.

Quadro 02: Fatores higiênicos e motivacionais de Herzberg

\begin{tabular}{|c|c|}
\hline $\begin{array}{c}\text { FATORES MOTIVACIONAIS } \\
\text { (Satisfacientes) }\end{array}$ & $\begin{array}{c}\text { FATORES HIGIÊNICOS } \\
\text { (Insatisfacientes) }\end{array}$ \\
\hline $\begin{array}{c}\text { CONTEÚDO DO CARGO } \\
\text { Como o indivíduo se sente em relação ao } \\
\text { CARGO }\end{array}$ & $\begin{array}{c}\text { CONTEXTO DO CARGO } \\
\text { Como o indivíduo se sente com relação à } \\
\text { EMPRESA }\end{array}$ \\
\hline $\begin{array}{l}\text { 1.Trabalho em si } \\
\text { 2. Realização } \\
\text { 3. Reconhecimento } \\
\text { 4.Progresso profissional } \\
\text { 5. Responsabilidade }\end{array}$ & $\begin{array}{l}\text { 1.Condições de trabalho } \\
\text { 2. Administração da empresa } \\
\text { 3. Salário } \\
\text { 4.Relações com o supervisor } \\
\text { 5. Benefícios e Serviços sociais }\end{array}$ \\
\hline
\end{tabular}

Fonte: Rufino(2007)

De acordo com as verificações feitas nesse estudo de Herzberg em que os fatores que produzem motivação no trabalho são distintos dos que conduzem à insatisfação (RUFINO, 2007, p. 39) observa-se sentimentos que não são opostos:

Observamos dois sentimentos que não são opostos um ao outro. O oposto de satisfação no trabalho não é insatisfação, mas, sim, nenhuma satisfação no trabalho; e, da mesma forma, o oposto da insatisfação no trabalho não é a satisfação, mas, nenhuma insatisfação no trabalho.

Uma importante potencialidade da teoria dos dois fatores de Herzberg (1973) está justamente no fato de o autor afirmar que há um conjunto de fatores que responde pela satisfação e outro conjunto de fatores que responde pela insatisfação do indivíduo no trabalho.

Entendendo que há diferenças entre a dinâmica organizacional de uma empresa privada e de uma organização pública, a seção seguinte abordará a motivação no serviço público. 
Id on Line Revista Multidisciplinar e de Psicoloqia

Id on Line Revista Multidisciplinar e de Psicologia

\section{Motivação no Serviço Público}

Conceituando o serviço público, Carvalho Filho (2010, p.350) descreve-o como sendo,

Toda atividade prestada pelo Estado ou por seus delegados, basicamente sob regime de direito público, com vistas à satisfação de necessidades essenciais e secundárias da coletividade.

Neste contexto, o servidor público tem a função de prestar serviços, exercendo suas atividades com seriedade, eficiência, presteza, educação, transparência, servindo unicamente os interesses da coletividade, sem fazer qualquer distinção e sem prejudicar qualquer indivíduo (KOHAMA, 2003).

Pode-se entender a motivação no setor público como uma predisposição que alguns indivíduos têm para responder às questões fundamentadas primária ou unicamente em instituições e organizações públicas e que é formada como uma combinação de atração ao funcionalismo, compromisso com valores públicos e compaixão (PERRY; WISE,2010).

Já François (2000) afirma que as repartições públicas são povoadas por funcionários públicos de alta motivação para o serviço. Nesse caso, há tendência dos funcionários em aceitar ganhos financeiros menores, pois sua recompensa advém da satisfação na prestação do serviço público.

Existe um senso comum de que os motivos dos funcionários públicos são diferentes dos motivos dos funcionários do setor privado (PERRY; WISE, 2010).A existência de diferenças sugere, portanto, a adoção de práticas de gestão de pessoas distintas. Enquanto nas empresas privadas haveria melhores condições para se obter maior produtividade a partir da oferta de fatores motivacionais externos, no serviço público o trabalho seria intrinsecamente mais satisfatório e recompensador, um ambiente assim fica caracterizado como um local cujo desempenho seria menos sensível a fatores motivacionais financeiros (FRANK;LEWIS, 2004).

Pode-se ainda admitir que servidores públicos dão menor importância aos fatores motivacionais extrínsecos (como remunerações, salários, benefícios) em comparação a funcionários do setor privado (PERRY; HONDEGHEM, 2008). Nessa perspectiva, pode-se afirmar que os servidores públicos são fortemente motivados por dimensões intrínsecas ou simbólicas do trabalho, tais como o altruísmo, comportamento pró-social, comprometimento com os objetivos institucionais, senso de dever, lealdade e prazer com o trabalho (PERRY; WISE, 2010).Assim, fatores motivacionais intrínsecos, não pecuniários - como a oportunidade de servir à sociedade e ao interesse público seriam mais importantes para funcionários públicos do que privados(CREWSON, 1997)

Para serem bem-sucedidas, as estruturas de recompensa do setor público devem ser concebidas além de somente recompensas monetárias, e devem fornecer uma oportunidade para satisfazer a motivação intrínseca de seus funcionários (HOUSTON, 2000).Os funcionários públicos tendem a colocar um valor maior na recompensa intrínseca do trabalho, ao sentimento de realização, 
Id on Line Revista Multidisciplinar e de Psicoloqia

Id on Line Revista Multidisciplinar e de Psicologia

tornando mais difícil colocar um valor alto em busca de recompensa motivadora extrínseca (ALVIM; MASCARENHAS, 2014).

Na ótica de Carvalho (2008), no serviço público há um círculo vicioso em que os servidores se sentem desvalorizados e esquecidos pelos governantes e desprestigiados pelos usuários dos seus serviços. Sendo assim, o autor sugere que

\begin{abstract}
Para criar um ambiente propício ao resgate e à manutenção da motivação do servidor público é preciso quebrar este círculo vicioso por meio de medidas concretas que valorizem os bons servidores, criando mecanismos objetivos para que os usuários ajam como verdadeiros clientes, exigindo um serviço público de qualidade e separando os que servem o público daqueles que se servem dele (CARVALHO, 2008, p. 62)
\end{abstract}

Finalizada a discussão dos temas que deram suporte teórico à presente investigação, a seguir serão apresentados os aspectos metodológicos.

\title{
Metodologia
}

A pesquisa científica segundo GIL (2008, p.26) é definida como: “(...) o processo formal e sistemático de desenvolvimento do método científico. O objetivo fundamental da pesquisa é descobrir respostas para problemas mediante o emprego de procedimentos científicos. Pode-se caracterizar esta investigação como pesquisa bibliográfica que foi realizada em livros, periódicos e artigos. De acordo com (GIL, 2008, p. 50), a pesquisa bibliográfica é "desenvolvida a partir de material já elaborado constituído principalmente de livros e artigos".

Para responder a problemática foi realizada uma pesquisa descritiva. As pesquisas descritivas têm como objetivo estudar as características de determinado grupo assim como sua renda, a distribuição da idade, sexo, nível de escolaridade e outros comportamentos que possam surgir (GIL, 2008).

$\mathrm{Na}$ presente pesquisa utilizou-se a abordagem quantitativa: (...) "o método quantitativo representa, em princípio, a intenção de garantir precisão dos resultados, evitar distorções de análise e interpretação, possibilitando, consequentemente, uma margem de segurança quanto às inferências" (RICHARDSON, 2010, p. 70).

A coleta de dados foi realizada por meio de um questionário, que segundo Gil (2009) é uma técnica de investigação composta por um conjunto de questões que são submetidas a pessoas com o propósito de obter informações e outros assuntos que venham surgir.

As perguntas do questionário foram elaboradas com base na teoria dos dois fatores de Herzberg. Dividido em três partes: a primeira consta o perfil dos servidores públicos entrevistados, a 
Id on Line Revista Multidisciplinar e de Psicoloqia

Id on Line Revista Multidisciplinar e de Psicologia

segunda e terceira abrange os fatores motivacionais (satisfacientes) e os Higiênicos (insatisfacientes), respectivamente.

O instrumento de medida adotado nesse estudo foi a escala de Likert de cinco pontos, definida como:

Uma escala de medida com cinco categorias de respostas que vão de discordo totalmente a concordo totalmente, e que exige que os participantes indiquem um grau de concordância ou de discordância com cada uma de uma série de afirmações relacionadas com os objetivos de estímulo (BRUNELLI,2008, p. 60).

Nas pesquisas quantitativas é muito frequente trabalhar com amostra, que significa trabalhar com uma pequena parte dos elementos que compõe o universo (GIL, 2008). Uma vez que o tamanho do universo desta pesquisa corresponde a 271 servidores obteve-se uma amostra representativa para este estudo formada por 160 servidores da secretaria de educação do município de Ponto Novo com erro amostral de $5 \%$ e nível de confiança de $95 \%$.

Os dados foram analisados através das questões afirmativas do questionário, respondidas pelos professores efetivos da rede pública municipal da Prefeitura de Ponto Novo-Ba. O questionário foi elaborado com 10 questões, sendo 05 sobre fatores motivacionais e outras 05 sobre fatores higiênicos, além das perguntas iniciais sobre o perfil dos entrevistados. Sendo que cada afirmativa gerou uma resposta que foi analisada e tabulada. Esses dados foram informatizados em arquivo eletrônico onde na oportunidade a análise foi feita com auxílio do programas do Office, Excel e Word.

Para análise dos dados, adotou-se a estatística descritiva que é a etapa inicial da análise utilizada para descrever, resumir e analisar a interpretação dos dados. Para Davila(2007, p. 5), "equivale a dizer que, para conferir maior clareza aos dados tabulados em um trabalho acadêmico, é preciso que os mesmos, além de apresentados em forma de gráficos ou tabelas, sejam explicados na forma de texto".

\section{Apresentação e análise dos dados}

Essa seção ocupa-se de apresentar e analisar os dados coletados conforme metodologia acima descrita.

\section{Caracterização do Município e do órgão municipal estudado}

Localizado na microrregião de Senhor do Bonfim e região econômica do Piemonte da Diamantina, Ponto Novo possui $465 \mathrm{~km}^{2}$ de área territorial, distante $328 \mathrm{~km}$ da capital, via BR-407, 
Id on Line Revista Multidisciplinar e de Psicologia

Id on Line Revista Multidisciplinar e de Psicologia

com uma população de 15.741 hab. (IBGE,2010) e limita-se com as cidades de Queimadas, Caldeirão Grande, Saúde, Pindobaçu e Filadélfia (SEI, 2016).

Atualmente, a prefeitura municipal é o maior empregador do município. Sua base econômica é a agropecuária, que incorpora a maior parte da mão-de-obra, na cidade possui o projeto de Irrigação da Barragem de Ponto Novo como maior empreendimento na região e as atividades comerciais que assumem um pequeno percentual. Dentre os órgãos municipais optou-se em tomar a Secretaria Municipal de Educação como campo de pesquisa.

Atualmente a Secretaria Municipal de Educação (SEMEC) conta com 271 professores concursados e 30 diretores e coordenadores nas escolas, esses profissionais são distribuídos em todas as unidades escolares. O município conta hoje com 30 unidades escolares entre escolas, núcleos, creches e anexos), sendo 09 na sede do município e os demais na zona rural, com aproximadamente 3.600 alunos matriculados (SEMEC, 2016).

\section{Perfil dos entrevistados}

Verificou-se que a maior parte dos participantes é do sexo feminino (84\%), com idade entre 31 a 50 anos (91\%), cerca de (72\%) possuem pós-graduação e tem mais de 10 anos de trabalho na instituição (71\%).

\section{Fatores Motivacionais}

Na questão 01, os dados revelaram que somados, os que concordam e concordam totalmente $56 \%$ sente-se reconhecidos pelo trabalho que executam, enquanto que $21 \%$ discordam e outros $15 \%$ discordam totalmente. Este resultado mostra que a maioria dos servidores se sente reconhecidos no seu ambiente de trabalho e acredita que o desempenho do seu cargo e o reconhecimento é um fator relevante para sua motivação.Nesse sentido, cabe lembrar que o reconhecimento do trabalho do colaborador, seja através de promoção ou de um elogio é fundamental no processo de estímulos e encorajamento do trabalhador com relação a sua função, além de despertar desejo constante de melhoria da atividades executadas (CHIAVENATO, 2004). 
Gráfico 01: Reconhecimento no trabalho

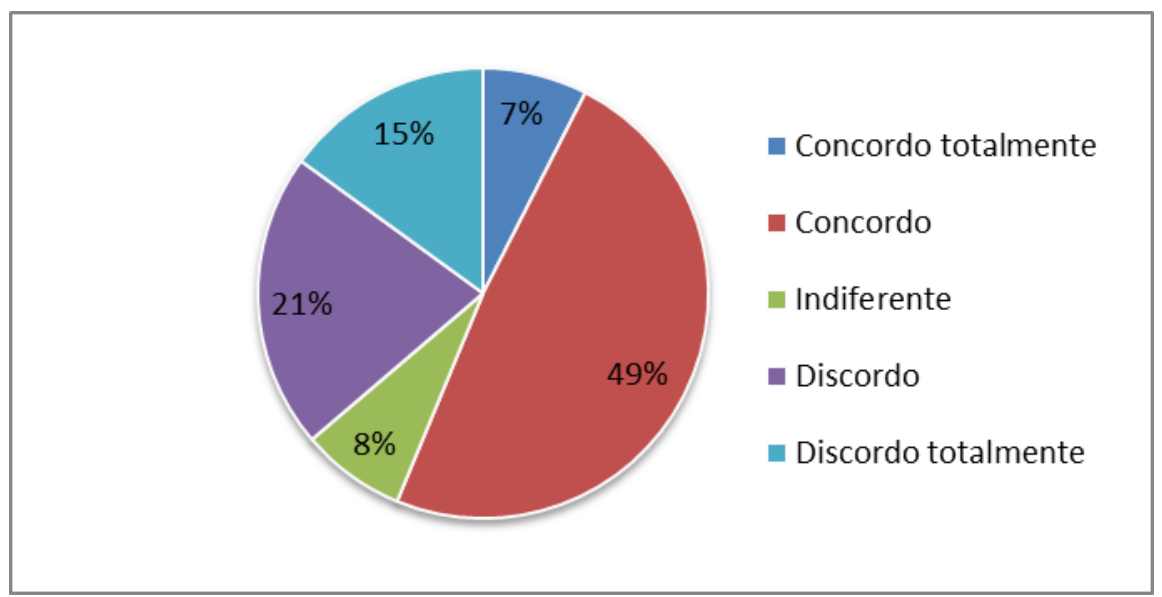

Fonte: dados da pesquisa

No que se refere a percepção dos funcionários sobre suas responsabilidades e obrigações na organização, o gráfico 02 mostra que $86 \%$ dos professores entrevistados concordam totalmente e os outros $14 \%$ concordam que tem responsabilidade no trabalho que realizam. Observa-se neste item que o fato desses funcionários se reconhecem como pessoas responsáveis é de grande valia e funciona como um fator estimulador da motivação de profissionais, como esclarece Bergamini (1997). Observase ainda que, esses sujeitostêm forte relação com as características dos profissionais relacionados na teoria Y de MCGregor, onde os colaboradores são competentes e responsáveis.

Gráfico 02: Responsabilidade com o trabalho realizado

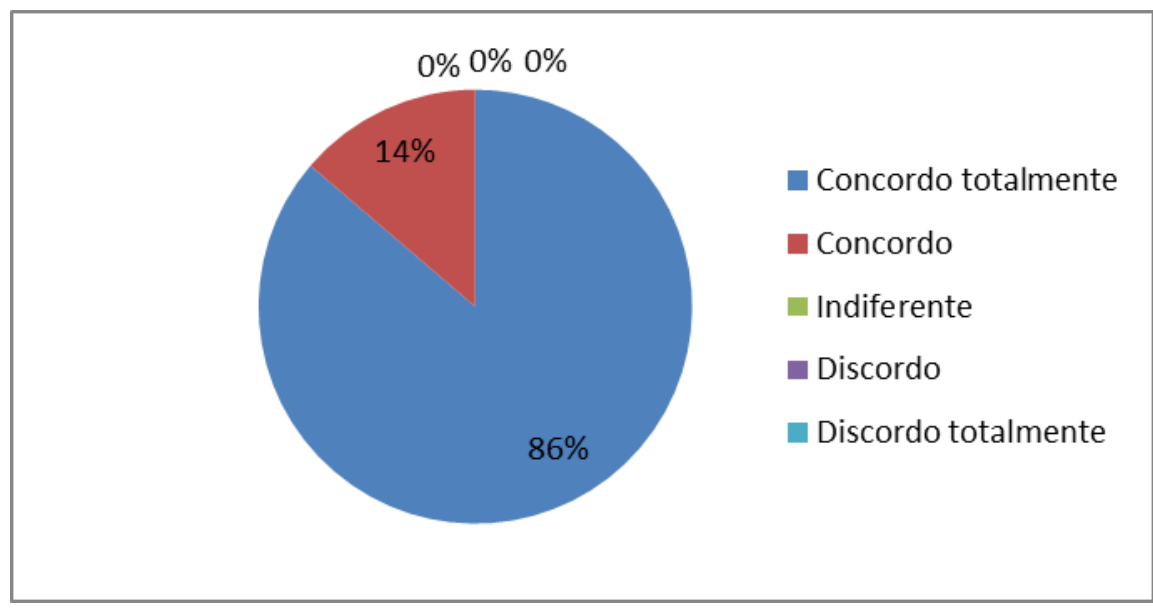

Fonte: dados da pesquisa

Em se tratando de satisfação no trabalho, no gráfico 03 observa-se que $90 \%$ dos respondente afirmam que estão satisfeitos com o seu trabalho. Verifica-se que uma pequena minoria discorda sobre essa afirmativa, somando apenas 5\%. Esse resultado é bastante relevante, pois significa que esses 
sujeitos têm um sentimento de realização com o seu trabalho, gostam do que fazem, tem o prazer e a satisfação pelo exercício da profissão, configurando-se caracteristicamente como os verdadeiros fatores responsáveis pela motivação intrínsecas, chamados de fatores motivacionais (CHIAVENATO, 2004).

Gráfico 03: Satisfação com o trabalho realizado

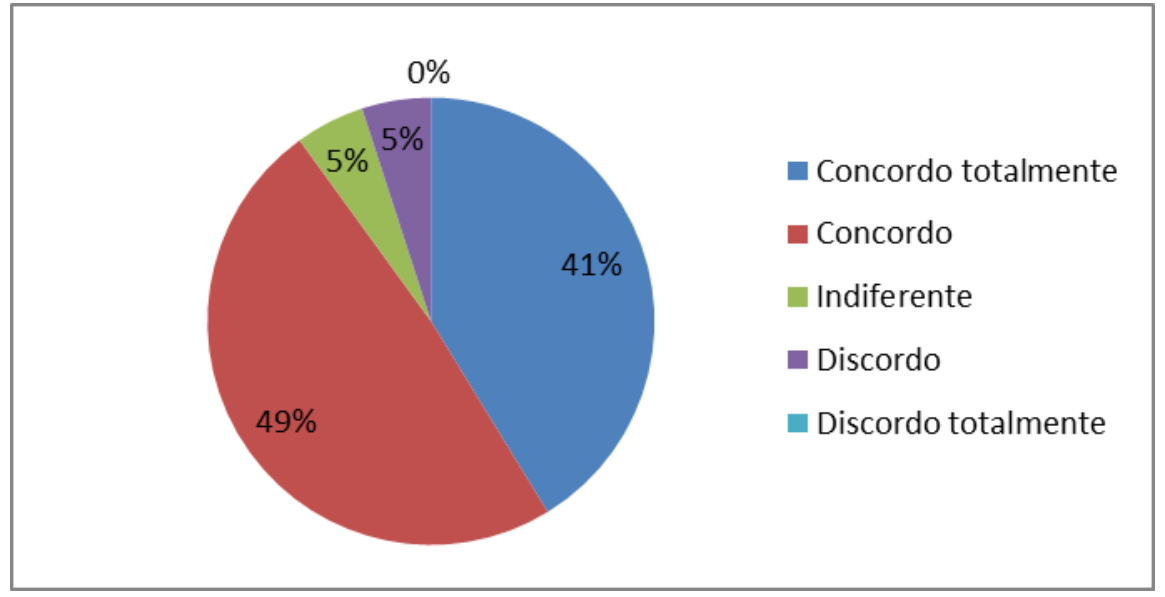

Fonte: dados da pesquisa

Importa destacar também que $83 \%$ dos professores afirmam ter desenvolvido profissionalmente dentro da organização, sendo reflexo de programas de capacitação e cursos de extensão, assim como jornadas pedagógicas realizadas anualmente. Esse aspecto é bastante positivo para a valorização desse funcionário público, pois, as oportunidades de crescimento dentro da organização deixam o indivíduo mais confiante e satisfeito no seu ambiente de trabalho, contribuindo assim para uma melhoria na qualidade do ensino (RUFINO, 2007).

Ao se questionar os servidores sobre a realização pessoal e profissional com o trabalho (Gráfico 04), a maioria respondeu que se sentem realizada, com índice de $86 \%$ entre os que concordam e concordam totalmente. Esse resultado é reflexo da evolução proporcionada ao profissional ao longo da carreira, como plano de carreira e programas de capacitação e treinamentos continuo. Esse aspecto de acordo coma teoria de Herzberg é um fator estimulador da motivação, pois o funcionário realizado tem maior satisfação e conseqüentemente melhor desempenho nas atividades desenvolvidas, como afirmou Rufino(2007). 
Gráfico 04: Realização pessoal e profissional com o trabalho

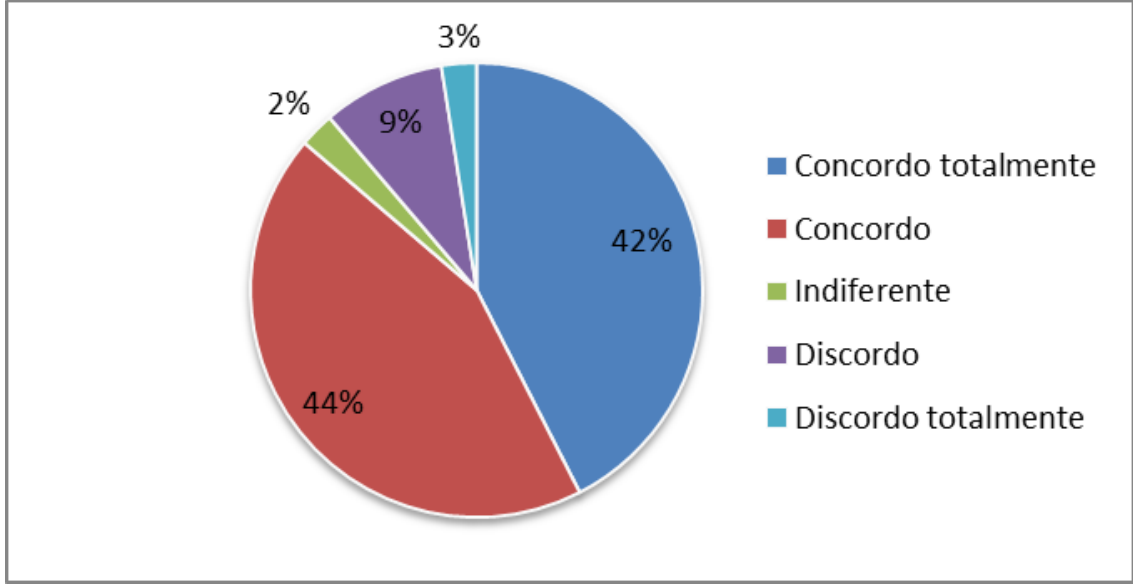

Fonte: dados da pesquisa

\section{Fatores Higiênicos}

No gráfico 05 pode-se observa que $96 \%$ declaram ter boas relações com o superior e a equipe de trabalho. Os resultados dessa questão revelam que há uma boa interação entre os servidores e um excelente contato do servidor com a chefia, fortalecendo a comunicação e o relacionamento no ambiente de trabalho, fatores visto como de grande relevância para a organização, relacionado por Herzberg como fator de natureza higiênica, que envolve as condições gerias do ambiente onde o colaborador esta inserido, assim como sua interação no grupo. Sendo o homem é um ser social, o mesmo possui necessidades de participar e interagir em grupos e ser aceito pelo mesmo. Isso aumenta a sua estima. (BERGAMINI, 1997). Nesse ponto, cabe a instituição prezar por esse ambiente de bom relacionamento entre os colaboradores, estimular a relação dos superiores com professores.

Gráfico 05: Relações com o superior e pessoas da equipe de trabalho

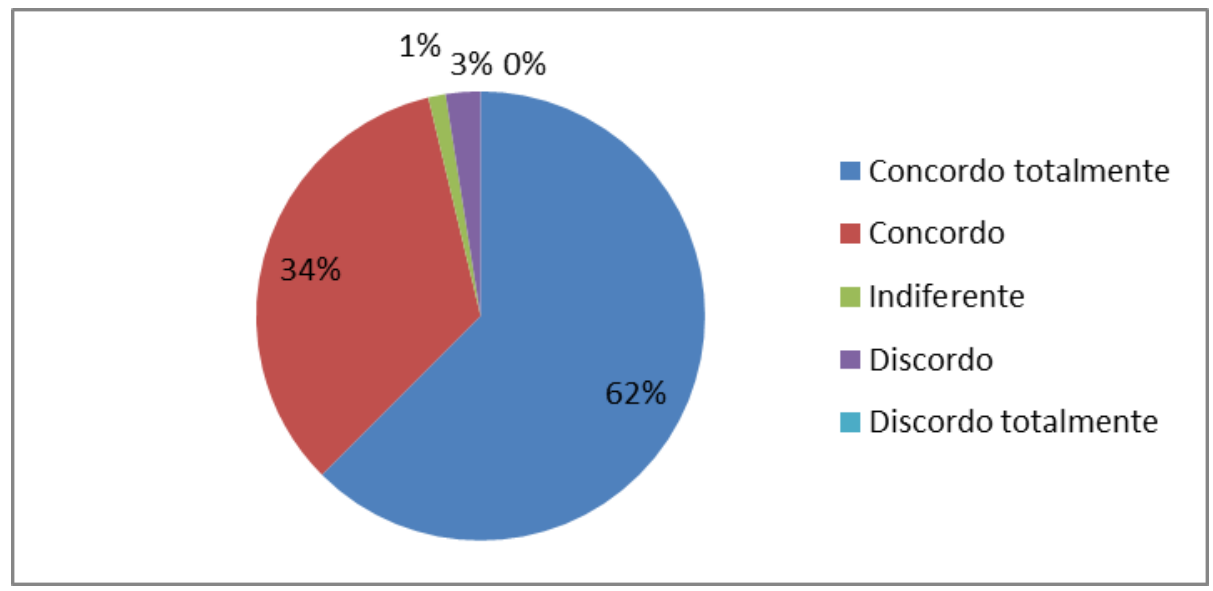

Fonte: dados da pesquisa 
Id on Line Revista Multidisciplinar e de Psicologia

Id on Line Revista Multidisciplinar e de Psicologia

Ao se abordar a adequação da remuneração com a realidade do servidor, $66 \%$ dos servidores estão insatisfeitos com a sua remuneração, enquanto que apenas $23 \%$ consideram-se satisfeitos. Os dados analisados nos mostram um alto nível de insatisfação dos funcionários com relação à remuneração. Como a remuneração para Herzberg é um fator higiênico, Nesse caso surge a insatisfação nos servidores. Diante desse cenário, conforme (RUFINO, 2007), tem que haver o desenvolvimento de políticas administrativas de remuneração, benefícios, promoções e bonificações, adequadas com a realidade do servidor e não restringir essas políticas apenas ao aumento salarial.

Os resultados da questão que tratou sobre as condições de segurança no trabalho mostraram que metade dos servidores (50\%) estão insatisfeitos com as condições de segurança, enquanto que $27 \%$ afirmam que as condições de segurança atendem as suas expectativas, porém $23 \%$ são indiferentes. O que chama atenção para esse percentual, é que muitos professores não sabem se o ambiente oferece ou não segurança. Neste caso a organização deve ficar atenta para a questão da segurança no ambiente de trabalho, pois em um local em que os funcionários se sintam inseguros, não existe uma boa produtividade, podendo ocasionar, conforme Herzberg, uma insatisfação devido a situação de segurança do ambiente e as condições de trabalho (RUFINO, 2007).

Sobre as atitudes e decisões tomadas pela administração, no gráfico 06 verifica-se que dentre os pesquisados, $51 \%$ estão insatisfeitos com esse fator, enquanto que apenas $21 \%$ estão de acordo. Importa ainda observar que neste item há uma parte significante de indiferentes com percentual de $28 \%$ talvez por conta de não quererem se envolver em questões políticas na instituição. Estes dados demonstram que as atitudes dos gestores e o processo de tomada de decisões não estão sendo aceitos pela maioria dos servidores ou as decisões estão partindo somente do topo da hierarquia, sem ouvir os demais servidores.Neste caso, sugere-se que a instituição reveja suas políticas de decisões, pois o indivíduo sente-se mais atraído por um trabalho que tenha crescimento pessoal e que são inseridos nos processos decisórios da organização (BERGAMINI, 1997).

Gráfico 06: Decisão e atitudes da administração

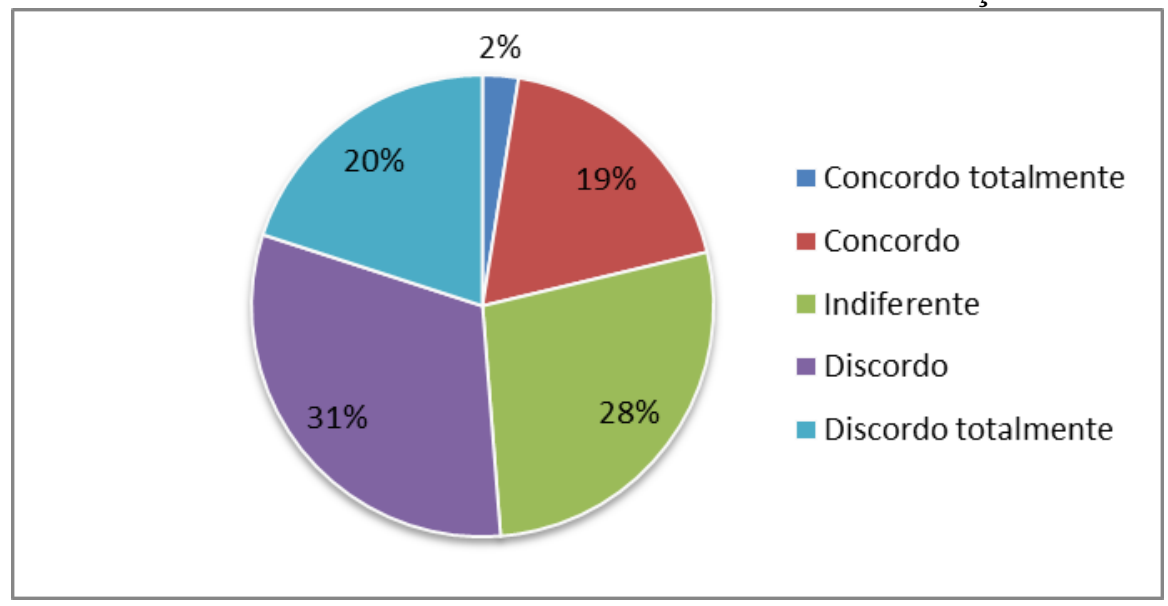

Fonte: dados da pesquisa 
Id on Line Revista Multidisciplinar e de Psicologia

Id on Line Revista Multidisciplinar e de Psicologia

Visando verificar o nível de orgulho em se trabalhar na organização pesquisada, o gráfico 07 mostra que 26\% não sentem orgulho de trabalhar na Prefeitura Municipal de Ponto Novo e 66\% sentem-se orgulhosos. Nesse ponto pode-se concluir que a organização pode até ser bem vista pelos seus funcionários, pois de certa forma, esses professores tem orgulho pela profissão e amor pela sala de aula, é o que afirma François (2000), “(...) que as repartições públicas são povoadas por funcionários públicos de alta motivação para o serviço, pois sua recompensa advém da satisfação na prestação do serviço público. Porém a organização necessita melhorar sua imagem através de práticas e desenvolvimento de políticas de valorização dos servidores, para assim, aumentar o nível de orgulho em trabalhar na instituição.

Gráfico 07: Orgulho de trabalhar na Prefeitura de Ponto Novo

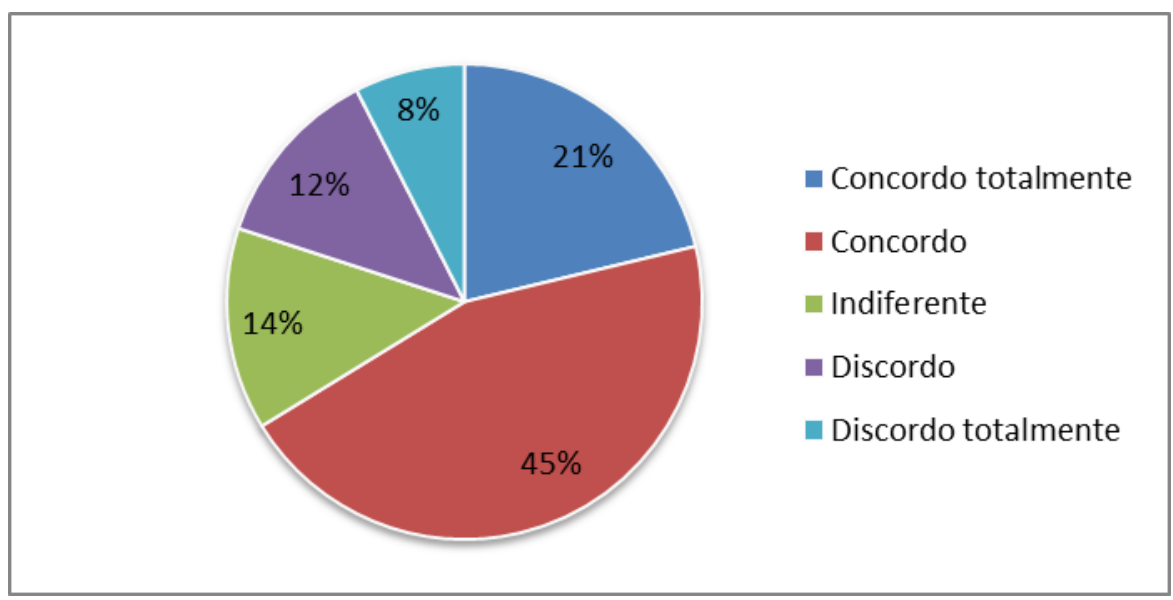

Fonte: dados da pesquisa

\section{Considerações Finais}

Este trabalho teve como objetivo analisar os fatores que influenciam o nível de motivação dos servidores públicos municipais de Ponto Novo-Ba, sendo escolhidos para a pesquisa, os professores efetivos da secretaria municipal de educação do município.

No referencial teórico apresentou-se os principais conceitos sobre motivação no trabalho com ênfase no setor público, tomando idéias de alguns autores como; Bergamini (1997), Bergue (2012), Chiavenato (2004) e Rufino (2007), e abordamos as principais teorias sobre motivação; Teoria das Necessidades de Abraham Maslow, Teoria X e Y (MCGregor), Teoria da Expectativa, Teoria da Realização e a Teoria dos dois fatores de (Frederick Herzberg), sendo essa última o principal aporte teórico da presente investigação.

Para responder ao objetivo proposto, além da pesquisa bibliográfica em livros, artigos e periódicos, foi realizada uma pesquisa descritiva com abordagem quantitativa, sendo a coleta de dados 
Id on Line Revista Multidisciplinar e de Psicoloqia

Id on Line Revista Multidisciplinar e de Psicologia

realizada por meio de questionário com as questões tomando por base a Teoria dos Dois Fatores de Herzberg. O questionário foi dividido em três partes, a primeira sobre o perfil dos servidores e as demais sobre os fatores motivacionais e higiênicos de Herzberg.

No que se refere aos fatores que causam a satisfação dos funcionários no ambiente de trabalho, com a análise das respostas, constatou que, os fatores motivacionais tais como reconhecimento, realização, progresso profissional, responsabilidade e trabalho em si, estão de acordo com as expectativas dos servidores, sendo os que mais contribuem para satisfação e motivação no trabalho. Assim, o estudo em questão revelou que os funcionários pesquisados apresentam um elevado grau de motivação, pois esses profissionais estão satisfeitos com as questões que tratam a respeito dos fatores motivacionais.

$\mathrm{Na}$ busca por verificar os fatores que geram a não satisfação entre os servidores públicos municipais, nesse estudo revelou-se que os servidores estão satisfeitos com os fatores motivacionais, o que elimina a possibilidade de não satisfação por parte desses colaboradores.

Quanto aos fatores que levam a insatisfação dos funcionários no seu ambiente de trabalho, verificou-se um grande percentual de servidores insatisfeitos com relação à remuneração, condições de segurança trabalho e decisões da administração. Sendo assim, tais aspectos devem receber atenção especial por parte da administração municipal.

Acredita-se que os dados aqui apresentados possam contribuir para auxiliar na modernização de processos dentro do âmbito municipal estudado. Por fim vale destacar a importância desse estudo para o setor público e estudantes da área, sugerindo-se que sejam incentivadas mais pesquisas nessa área, pois quanto mais se aprofundar nesse assunto, maiores serão os retornos para esse campo de estudo e melhoria na motivação dos servidores que atuam na gestão pública no nível municipal.

\section{Referências}

ALVIM, Fábio: MASCARENHAS, André. Motivação no Serviço Público: Efeitos Sobre a Retenção e Satisfação Profissional dos Gestores Governamentais. XXXVIII ANPAD - Rio De Janeiro. 2014.

BERGAMINI, Cecília Whintaker. Motivação nas organizações. 4ª Ed. São Paulo: Atlas, 1997.

BERGUE, Sandro Trescastro. Comportamento Organizacional. Florianópolis: Departamento de Ciências da Administração/UFSC-CAPES/UAB, 2012.

BRESSER-Pereira, Luiz Carlos. Princípios Básicos de Administração Pública. Comunicação a $4^{\mathrm{a}}$ reunião anual do (Ecosoc) das Nações Unidas. Nova Yorque, 2005.

BRUNELLI, Maria da Graça. Motivação no Serviço Público. 2008. Tese (Pós-Graduação em MBA em Gestão Pública). Faculdade IBGEN, Porto Alegre-RS. 
Id on Line Revista Multidisciplinar e de Psicoloqia

Id on Line Revista Multidisciplinar e de Psicologia

CARVALHO FILHO, J. S. Manual de direito administrativo. 23. ed. Rio de Janeiro: Lumen Juris, 2010.

CHIAVENATO, Idalberto. Gestão de Pessoas: o novo papel dos recursos humanos nas organizações. $3^{\circ}$ Ed. Rio de Janeiro. Elsever, 2010.

CHIAVENATO, Idalberto. Recursos Humanos: o capital humano das organizações. $8^{\circ}$ Ed. São Paulo. Atlas, 2004.

CREWSON, P. E. .Public-service motivation: building empirical evidence of incidence and effect. Journal of Public Administration Research and Theory, 7(4), 499-518. 1997.

FRANCOIS, P. Public service motivation as an argument for government provision. Journal of Public Economics, v. 78, p. 275-299, 2000

FRANK, S.A. \& Lewis, G.B. Government employees: working hard or hardly working? American Review of Public Administration, Vol. 34 No. 1, 36-51, 2004.

GIL. Antonio Carlos. Métodos e técnicas de pesquisa social. 6 ed. São Paulo. Atlas, 2008.

GLASSER, William. Administração de Liderança: Qualidade e eficácia com uma moderna técnica de gerenciamento. 1 ed. São Paulo. Bestseller, 1994.

HOUSTON, D.J. Public-service motivation: a multivariate test. Journal of Public Administration Research \& Theory (Transaction), v. 10, n. 4, p. 713-727, 2000.

Instituto Brasileiro de Geografia e Estatística - IBGE. Disponível em: http://www.censo2010.ibge.gov.br/primeiros_dados_divulgados/index.php?uf=29>Acesso em: 05 Abril de 2016.

KHOAMA, Heilio. Contabilidade Pública: Teoria e Prática. 10 Ed. São Paulo. Atlas, 2006.

MALIK, A. M. Gestão de Recursos Humanos. Volume 9. São Paulo: Fundação Peirópolis Ltda, 1988.

PERRY, J. L. \& HONDEGHEM, A. Motivation in public management: the call of public service. New York: Oxford University, 2008.

PERRY, J. L., \& WISE, L. R. The motivational bases of public service. Public Administration Review, 50(3), 367-373, 2010.

RICHARDSON, Roberto Jarry. Pesquisa social: Métodos e Técnicas. $3^{\text {a }}$ Ed. São Paulo. Atlas, 2010.

ROBBINS, Stephen P. Comportamento organizacional. 11ª Ed. São Paulo. Pearson, 2009.

RODRIGUES, Claudia M. Cruz. RUFINO, Walmir da Silva. Motivação na Organização. $1^{\circ}$ Ed. São Paulo. Atlas, 2007.

SANTOS, Glauber Eduardo de Oliveira. Cálculo amostral: calculadora on-line. Disponível em: <http://www.calculoamostral.vai.la>. Acesso em: 25 de Maio de 2016. 
Superintendência de Estudos Econômicos e Sociais da Bahia - SEI. Disponível em: http://www.sei.ba.gov.br/images/inf_sociopopulacionais/censo_2010/resultados_do_universo/cartogra mas/populacao_total/2010/poptotalpiemontedonortedoitapicuru.pdf. Acesso em 05 de Abril de 2016.

VERGARA, Sylvia Constant. Gestão de Pessoas. $4^{\circ}$ Ed. São Paulo. Atlas, 2005.

\section{Como citar este artigo (Formato ABNT):}

DOMINGOS JÚNIOR, A.P.; BARBOSA, M.A.C. Motivação no Setor Público: um estudo com servidores do município de Ponto Novo - BA. Id on Line Revista Multidisciplinar e de Psicologia, Julho de 2016, vol.10, n.30, Supl 2, p. 08-24. ISSN 1981-1179.

Recebido: 10/06/2016

Aceito: 16/06/2016 